\title{
The Effectiveness of Therapy Based on Acceptance and Commitment Social Anxiety and General Self-Efficacy on Divorced Women Under Welfare Organization in Yazd
}

\author{
Mozhgan Shaker ${ }^{1}$, Mehdi Rahimi ${ }^{\star}$ and Maryam Zare ${ }^{2}$ \\ ${ }^{1}$ Department of Clinical Psychology, Yazd Science and Research Branch, Islamic Azad university, Yazd, Iran
}

${ }^{2}$ Department of Education and Psychology, Faculty of Humanity Sciences, Yazd University, Yazd, Iran

\begin{abstract}
This research is carried out targeting the assessment of effectiveness of group therapy based on acceptance and commitment on social avoidance and general self-efficiency among the divorced women from Yazd City who are supported by Welfare Organization. At first, two centers were selected among the clinics and communities associated with Welfare using availability method, the women were asked to complete the questionnaires on social pressure, and avoidance and general self-efficiency.in the next stage, 60 people who scored the least from the questionnaires were randomly divided into two test and control groups. Then 8 therapy sessions were held for the test group. In the meantime, the control group received no therapy. After these sessions, both groups were posttested again. The result of covariance analysis showed that in the post-test of the test group, the social avoidance score decreased. Therefore, we could conclude that group training of this therapy is effective on decreasing the social avoidance of general self-efficiency of divorced women.
\end{abstract}

Keywords: Commitment and acceptance based therapy; Social avoidance; General self-efficiency; Divorce

\section{Introduction}

Family has a important and effective role amongst the social organizations and institutions. In other words, family is the foundation of society. Moreover, this institute provides its members with the feeling of comfort and safety. It is among the most lasting institute within a thousand years, which preserve the cultural characteristics, and is the agent of transferring them to the next generation. When the desired functions of family are faced with serious difficulties and continuing of marriage will gain more troubles than the consequences of divorce, Islam has given the order to proximity and preponderance and even the necessity to divorce. Divorce is one of the most important phenomena of humankind's life, which interfere with both mental balance of couple and their kids and close relatives.

Effects of divorce are not just on family members but also the social effects should not be ignored. No doubt some young offenders are from families with mental and emotional disorders are a family conflict. The criminal psychology of social deviance and socially disadvantaged groups or community rejection and emotional injuries sometimes result in children in families of divorce is detected [1-5].

Among the problems after the divorce, economic hardship and psychological problems of anxiety and depression (each with 41 percent) the most problems is people, especially women after divorce (and healthy). Almost certainly we can say that some of the abnormal gene underlying pathological anxiety states, and on the other hand evidence suggests that traumatic life events and stress also are important in the etiology of anxiety disorders. Kendall Treadwell (1996, quoted Moore 3, 2010) Believe those who are anxious more negative statements about themselves to people who are not distressed. Some adults with anxiety, avoiding social situations 4 and with a few friends and are more likely to have lower unemployment and social Persons of their abilities are less anxious waiting for them at the moment of anxiety focused on cognitive processes that makes these people have low self-efficacy perception and people who are self- 6 to easily helplessness poor.
Since when families break apart, women and children experienced the biggest drop in living standards And Divorced women after divorce, loneliness and lack. It makes them bitter and painful in public and avoid its functionality and performance at a low level due to the mentioned factors and evaluate the important role of women in society, necessity It is felt that these women can take Rabala automatically because your Amadi Amadi up automatically lead to better management issues in the family. And also makes the inevitable fear in the community, to appropriate interactions with community members make sense of their lives once again. Hayes findings, Pystrvla suggests that treatment based on acceptance and commitment as integrated model for behavior modification that focuses on six main processes (reception, faulting 10 itself, time, values and practice committed) acts and these processes have only a single goal and that mental flexibility, and stated that this treatment can positively change people's behavior and personal development and provide developmental fields [6-12].

This study attempts to Examine whether a group based on acceptance and commitment therapy can reduce social anxiety and general self-efficacy in increasing divorced women.

\section{Research Hypotheses}

\section{The main hypothesis}

Is Group Based on acceptance and commitment therapy to reduce social anxiety and Increase the efficacy of divorced women under welfare organization Yazd City.

*Corresponding author: Rahimi M, Department of Education and Psychology faculty of humanity sciences, Yazd university, Yazd, Iran, Tel: + 38 (066) 95502 25; E-mail: mohsen8203934@yahoo.com

Received: June 07, 2016; Accepted: July 06, 2016; Published: July 13, 2016

Citation: Shaker M, Rahimi M, Zare M (2016) The Effectiveness of Therapy Based on Acceptance and Commitment Social Anxiety and General Self-Efficacy on Divorced Women Under Welfare Organization in Yazd. Clin Exp Psychol 2: 137. doi: 10.4172/2471-2701.1000137

Copyright: (C) 2016 Shaker M, et al. This is an open-access article distributed under the terms of the Creative Commons Attribution License, which permits unrestricted use, distribution, and reproduction in any medium, provided the original author and source are credited. 


\section{Lateral hypothesis}

Is Group Acceptance and commitment therapy based on reducing social avoidance under welfare organization becomes divorced women?.

\section{Research background}

Examined the relationship between social anxiety and social self-efficacy and body image among female students of Islamic Azad University Branch have conducted research on 240 students The results of their study showed a significant negative correlation between social anxiety and body image, but there is a positive relationship between social self-efficacy and body image. Stated that people who have body image dissatisfaction, fear of negative evaluation more to evaluate the effectiveness of acceptance and commitment therapy on pain and pain-related anxiety and pain acceptance of male patients with chronic pain have a sample consisted of 30 male patients with chronic pain, and Isfahan University of Medical Sciences were referred Sheltered 8 sessions of group therapy were based on acceptance and commitment and the results showed that treatment with increased acceptance of pain and anxiety associated with pain and severity of pain [13-16].

The population in this study, 30 women betrayed referred to counseling centers in Shiraz who were randomly divided into experimental group in 10 sessions and each session for 90 minutes as based on acceptance and commitment treatment groups was the results showed that the treatment is effective on forgiveness and marital adjustment.

They were told that measures should be taken of nurse managers of self-efficacy do in order to by increasing self-motivation increases. As well as their results showed that self-efficacy is associated with age and education related to gender. When self-development and development will also find motivation in his study based on acceptance and commitment therapy for psychological adjustment, social adults with stuttering, on 20 adults who stutter have worked Oct 8 consecutive weeks, the results showed that an integrated program treatment as an effective intervention in mental function, prepare for change and treatment is effective. It also improves mental health and reduce the negative impact on the course of their lives is stuttering.

\section{Research method}

The aim of the present study is an applied research component. The purpose of this research is to find principles that are applied in real situations and practical product improvement and efficiency and help procedures. And in terms of data collection of quasi-experimental research is. Once this plan is that the main purpose of research, experiment and the reaction is Asrkhasy. In this study, the independent variable period based on acceptance and commitment therapy and social variables and general self-efficacy is avoided [17-23].

In this study, the subjects were randomly selected and divided into two groups: experimental and control as much as possible with both groups and the results of the test of both groups are in order to assess dependent variable comparison.

\section{The population and sample}

The population in this study consisted of all divorced women under welfare organization in the city of Yazd is that, in order to determine the minimum sample size required, firstly to approach from those clinics and centers affiliated to the center of the women's well-being 2 asked social avoidance and general self-efficacy questionnaire and the pressure was complete. And then 60 people who received the lowest score from the questionnaires were randomly assigned to two groups of 30-person experimental and control groups.

\section{Procedure}

In this study, a sample size of 60 patients was determined randomly in two groups of 30 people (a test group and a control group) were divided and inventory pressure, and social avoidance Watson and Friend and general self efficacy questionnaire Schwartz and Jerusalem were distributed among them. The course of treatment based on acceptance and commitment in 8 sessions on the experimental group was only 90 minutes. During this period, the control group did not receive anything. After the course is based on acceptance and commitment therapy on experimental group and avoid social pressure and general self-efficacy questionnaire of both groups were (Table 1).

\section{Statistical analysis methods}

In this study, statistical methods, descriptive and inferential statistics using SPSS software. Used. In this study, the descriptive statistics of the maximum and minimum mean, standard deviation data, frequency tables and charts have been used as well as inferential statistics is because of the type of intervention that includes analysis of covariance is used. Information collected in two descriptive and inferential statistics using SPSS software and analyzed [24-30].

\section{Descriptive findings}

Table 2 shows the age breakdown of the sample group membership control and experimental groups show. As is evident in the experimental group members form samples were distributed almost evenly between age groups, but in the control group, most members are aged between 32 and 38 years.

In addition, Table 3 educational status of members of the sample to show the breakdown of membership in the experimental and control

Pre- test scores and avoid social pressure : 18.31 General self - efficacy pre - test scores : 21.86 Relationship therapy Education on family management after divorce How divorce in family interacts and has become a problem in their life Education and acceptance and commitment therapy and its goals Metaphor two mountains

First session

Frustration is not the solution, it's the problem

Survey the specific control strategies that a person has already been used Survey the costs and damages that this strategies have in life Survey the effects of this contro strategies Introduce control strategies as a problem Metaphor a person in the well

Introduce and promote its adoption

Focusing on control as a useless strategy in dealing with anxiety Outside control against internal Metaphor of two scales Metaphor tug monsters Guest metaphor and pauper

Not admixture cognitive Fiber himself Introduce kinds of itself Metaphor bus Metaphor chess surface

Teach aware mind strategy to promote life in every moment Teach aware mind for daily Do aware mind exercises of breath, mind and ignition

Clarify values ( prior to be valuable ) The primary easurement values Exercises to clarify values

Create larger patterns act responsibly Setting goals Identify internal and external obstacles Generalizing skills to act responsibly The scores after pressure and social avoidance : 8.23 General self - test scores : 32.33

Table 1: Methods in this study were designed in eight -60 minutes 
groups. As is evident, in both experimental and control groups, mostly members of the sample group of people have formed a high school diploma. The following Table 4 shows the mean and standard deviation variables to separate membership in the experimental and control groups, respectively.

\section{Results}

In this section to test the research, hypotheses will be discussed. To evaluate the effectiveness of therapy based on acceptance and commitment on the dependent variables of the study used analysis of covariance. For this purpose, the assumptions were studied. In this regard, the Kolmogorov-Smirnov test normal distribution of variables was investigated. Table 4 shows the results of this test.

Based on Table 5, the distribution of all the variables are not significantly different from the normal distribution. So the research hypotheses can be used parametric tests. Linearity of the relationship between pre-test and post-test followed by dispersion charts were reviewed and approved scatter plots related to social anxiety and selfefficacy.

Based on Table 6, the distribution of all the variables are not significantly different from the normal distribution. So the research

\begin{tabular}{|c|c|c|c|}
\hline Group & Age & Number & Percentage \\
\hline test & $18-24$ & 6 & 20 \\
\hline & $25-31$ & 8 & 26.7 \\
\hline & $32-38$ & 8 & 26.7 \\
\hline & $39-45$ & 8 & 26.7 \\
\hline & total & 30 & 100 \\
\hline & $18-24$ & 5 & 16.7 \\
\hline & $25-31$ & 9 & 36.7 \\
\hline & $32-38$ & 11 & 30 \\
\hline & $39-45$ & 5 & 16.7 \\
\hline & Total & 30 & 100 \\
\hline
\end{tabular}

Table 2: The age distribution of the sample group.

\begin{tabular}{|c|c|c|c|}
\hline Group & Education & Number & Percentage \\
\hline Test & High school diploma & 21 & 70 \\
\hline & Diploma & 8 & 26.7 \\
\hline & Associate degree \& B.A. & 0 & 0 \\
\hline & M.A. & 1 & 3.3 \\
\hline Control & total & 30 & 100 \\
\hline & Lower school diploma & 15 & 50 \\
\hline & Diploma & 9 & 30 \\
\hline & Associate degree \& B.A. & 6 & 20 \\
\hline & M.A. & 0 & 0 \\
\hline & Total & 30 & 100 \\
\hline
\end{tabular}

Table 3: Education distributed sample.

\begin{tabular}{|c|c|c|c|c|c|c|}
\hline Group & Variable & Group & average & $\begin{array}{c}\text { Standard } \\
\text { deviation }\end{array}$ & min & max \\
\hline Test & Social avoidance & Pre test & 18.13 & 6.62 & 1 & 27 \\
\hline & & Posttest & 8.23 & 6.62 & 1 & 26 \\
\hline & $\begin{array}{c}\text { General self }- \\
\text { efficacy }\end{array}$ & Pre test & 21.86 & 7.26 & 11 & 36 \\
\hline Control & Social avoidance & Pre test & 16.63 & 7.27 & 4 & 27 \\
\hline & & Posttest & 15.33 & 4.53 & 4 & 21 \\
\hline & $\begin{array}{c}\text { General self - } \\
\text { efficacy }\end{array}$ & Pre test & 22.13 & 7.75 & 11 & 36 \\
\hline & & Posttest & 21.96 & 6.91 & 11 & 37 \\
\hline
\end{tabular}

Table 4: The mean and standard deviation of variables. hypotheses can be used parametric tests. Next, the homogeneity of the pre-test and post-test slope of the regression dependent variables in experimental and control groups were analyzed by analysis of variance. Table 7 shows the results [31-35].

As Table 8 shows, the interaction was not significant, the slope of the regression dependent variable of the pre-test in both groups are homogeneous. In addition, Table 8 Levin to study the homogeneity of variance test results in two experimental and control groups, respectively.

The results show that the variance is homogeneous in the variable social avoidance, but in the case of self-efficacy variable was a significant difference between the experimental and control groups variance there. But since the number of members of both groups is the same, we can not ignore the violation of assumptions. Therefore, in accordance with the basic assumptions of analysis of covariance, continuing research hypotheses are tested.

Hypothesis based on acceptance and commitment therapy, reduces social anxiety. To investigate this hypothesis of covariance was used. So social avoidance test between the experimental and control groups were compared with control pilot. Table 9 shows the results of analysis of covariance.

The results in Table 9 show that the two experimental groups and one control with pilot control are significant differences in terms of social avoidance and membership in the experimental group, $36 \%$ of the variance is explained by social anxiety.

The results show that membership in the group has been able to avoid testing and treatment community to substantially reduce than the control group.

\section{The Theoretical Explanation of Findings}

The first about the effectiveness of group therapy based on acceptance and commitment on the reduction of divorced women had social anxiety, social avoidance average $23 / 8 \mathrm{X}=$ experimental group and the control group was $33 / 15 \mathrm{X}=$. By comparing these scores determine which treatment is effective in reducing social anxiety. Given the low scores on scales measuring social avoidance symptoms less inevitable decrease reflects the scores after the intervention treatment success.

Second hypothesis, on the effectiveness of group therapy based on acceptance and commitment to increasing the efficacy of divorced women. Results obtained in the second hypothesis suggests that education based on acceptance and commitment group therapy, efficacy in this group of people has increased. Mean efficacy in the treatment group $33 / 32 \mathrm{X}=$ In the control group $13 / 22 \mathrm{X}=$ respectively. By comparing the average can be concluded that the training group therapy based on acceptance and commitment in the experimental group had an impact [36-40].

\section{Research Limitations}

This study has limitations such as a lack of suitable locations, funding, lack of cooperation by some authorities, and the inability researcher has faced in controlling unwanted variables. Due to time constraints, follow the continuity of results obtained in this study was not possible.

\section{Research Proposals}

In this section, according to the results of applied research proposals being presented to the authorities. In addition to practical 
Citation: Shaker M, Rahimi M, Zare M (2016) The Effectiveness of Therapy Based on Acceptance and Commitment Social Anxiety and General SelfEfficacy on Divorced Women Under Welfare Organization in Yazd. Clin Exp Psychol 2: 137. doi: 10.4172/2471-2701.1000137

Page 4 of 5

\begin{tabular}{|c|c|c|c|}
\hline Variable & & Free degree \\
\hline & Circumstantial evidence & 60 & significant \\
\hline Social avoidance & 0.104 & 0.16 & 60 \\
\hline
\end{tabular}

Table 5: Normality test results.

\begin{tabular}{|l|l|l|l|l|l|}
\hline Variable & Source variance & ss & df & ms & f \\
\hline Social avoidance & Pre test & 450.37 & 11 & 40.94 & 1.29 \\
\hline General self - efficacy & Pre test & 532.12 & 12 & 4.343 & 0.28 \\
\hline
\end{tabular}

Table 6: Levine test to check the homogeneity of variance.

\begin{tabular}{|c|c|c|c|}
\hline Variable & F & DF1 & DF2 \\
\hline Social avoidance & 3.15 & 1 & 58 \\
\hline General self - efficacy & 4.21 & 1 & 0.08 \\
\hline
\end{tabular}

Table 7: Covariance analysis of social avoidance.

\begin{tabular}{|c|c|c|c|c|c|}
\hline Source & SS & DF & MS & F & Pta Square \\
\hline Pre test & 258.49 & 1 & 258.49 & 0.15 & 0.002 \\
\hline group & 846.05 & 1 & 846.05 & 0.001 \\
\hline error & 1451.53 & 57 & 25.46 & \\
\hline total & 2466.18 & 59 & & \\
\hline
\end{tabular}

Table 8: Adjusted average social avoidance.

\begin{tabular}{|c|c|c|}
\hline Group & Average & Standard error \\
\hline Test & 8 & 0.92 \\
\hline Control & 15.56 & 0.92 \\
\hline
\end{tabular}

Table 9: Adjusted average standard error.

proposals, suggestions and recommendations for future research are presented to researchers in this field to new research opens the door steps enrichment research and theoretical literature are in the field.

\section{Reference}

1. Dale H (2003) Self-efficacy for reading and writing: Influence of modeling, goal setting, and self-evaluation. Reading and Writing Quarterly 19: 159-172.

2. Clark DA (2001) A Cognitive Perspective on Social Phobia. International Handbook of Social Anxiety: Concepts, Research and Interventions Relating to the Self and Shyness.

3. Bahadari Khosroshahi J, Khan Zainab (2013) The relationship between coping strategies and self-oriented substance abuse among students. Knowledge and Research in Applied Psychology 14: 90-80

4. Handestori K (2005) Social Skills among Socially Anxious Children in Iceland Institute and State University in partial fulfillment of the requirements for the degree of Master of Science in Clinical Psychology.

5. Azizli BE, Atkinson HM, Baughman EA, Giammarc N (2015) Relationships between general self-efficacy, planning for the future, and life satisfaction. Personality and Individual Differences 82: 58-60.

6. Hofmann SG, Bitran S (2007) Sensory-processing sensitivity in social anxiety disorder: Relationship to harm avoidance and diagnostic subtypes. J Anxiety Disord 21: 944-954.

7. Ezadi R, Abedi Mohammad Reza (2014) Acceptance and Commitment Therapy.

8. Lundgren T, Herbert D, Melin L, Dahl B (2006) Evaluation of Acceptance and Commitment Therapy for Drug Refractory Epilepsy: A Randomized Controlled Trial in South Africa-A Pilot Study obias. International League Against Epilepsy 47: 2173-2179.

9. Bandura A (1994) Self-efficacy. Encyclopedia of mental health pp. 71-81.

10. Bandure A (1982) Self_Efficacy Mechanism Hb Human Agency. Coping By A merican Psychological Association Inc 37: 122-147.

11. Campbell MA (1996) Does social anxiety increase with age?. Australian Journal of Guidance and Counselling 6: 43-52.
12. Davies CD, Niles AN, Pittig A, Arch JJ, Craske MG (2015) Physiological and behavioral indices of emotion dysregulation as predictors of outcome from cognitive behavioral therapy and acceptance and commitment therapy for anxiety Original Research. J Behav Ther Exp Psychiatry 46: 35-43.

13. Dalrymple KL, Herbert JD (2007) Acceptance and Commitment Therapy for Generalized Social Anxiety Disorder A Pilot Study. Behav Modif 31: 543-68.

14. Dana A, Weiser Daniel J, Weiger (2016) self-efficacy in romantic relationships: direct and indirect effects on relationship maintenance and satisfaction. Personality and Individual Differences 89: 152-156.

15. Erozkan D, Deniz S (2012) The influence of social self-efficacy and learned resourcefulness on loneliness. The Online Journal of Counselling and Education 1: 2

16. Harley H (2015) Bridging the Gap between Cognitive Therapy and Acceptance and Commitment Therapy (ACT). Journal of Procedia - Social and Behavioral Sciences.

17. Hayes SC, Pistorello J, Levin ME (2012) Acceptance and Commitment Therapy as a Unified Model of Behavior Change. The Counseling Psychologist 40: 976 1002.

18. Hoaly K, Asplund K, Andersson G (2014) Stress management for middle managers via an acceptance and commitment-based smartphone application: A randomized controlled trial. Journal homepage Internet Intervention 1: 95-101.

19. Kameli J (2007) Investigate the causes and factors contributing to the social damage of divorce Iran.

20. Leary MR (1982) Social anxiety. Review of personality and social psychology Beverly Hills 3: 641-669.

21. Low X (2011) Running head: Acceptance And commitment Therapy Treating adult Survivor Of Childhood Maltreatment With Acceptance And Commitment Therapy. Unpuplished mastr's thesis, nona State University.

22. Moran, Daniel J (2011) ACT for Leadership: Using Acceptance and Commitmen Training to Develop Crisis-Resilient Change Managers. The International Journal of Behavioral Consultation and Therapy 6: 341-355.

23. Moree B (2010) Social Anxiety in Children. Unpublished Master's thesis, Louisiana State University. 
Citation: Shaker M, Rahimi M, Zare M (2016) The Effectiveness of Therapy Based on Acceptance and Commitment Social Anxiety and General SelfEfficacy on Divorced Women Under Welfare Organization in Yazd. Clin Exp Psychol 2: 137. doi: 10.4172/2471-2701.1000137

Page 5 of 5

24. Hussein N (2009) Life Skills students. Tehran Welfare Organization Department of Public Relations 2: 128.

25. Psychiatric Association of America (2002) Text revised Diagnostic and Statistical Manual of Mental Disorders (MR Nikkhooi and Hamayak Vadys Yancey).

26. Zhang Z, Zhang CG, Zhang X, Liu X, Zhang H, et al. (2015) Relationship between self-efficacy beliefs and achievement motivation in student nurses, journal homepage. Chinese Nursing Research 2: 67-70.

27. Pankey J, Hayes Steven C (2003) Acceptance and commitment therapy for psychosis. International Journal of Psychology and Psychological Therapy 2: 311-328

28. Redmond B (2010) Self-Efficacy and Social Cognitive Theories - Work Attitudes and Job Motivation - Confluence.

29. Schlenker BR, Leary MR (1982) Social Anxiety and Self-Presentation: A Conceptualization. Jornal of Psychological Bulletin 92: 641-669.

30. Tarkhan M, Esmaeilpour M, Tizdast T (2013) A study relationship btween social aneixty, social self_efficacy and body image in the students of the Islamic Azad University at Tonecabon Branch. European Online Journal of Natural And Social Sciences 2: 510-515.

31. Zajacova A, Lynch Scott M, Thomas J, Espenshade (2005) Self-efficacy, Stress, And Acadamic Success In Colleg. Journal of Research in Higher Education 6: 677-706.
32. Zulkosky K (2009) Self-Efficacy: A Concept Analysis. Journal Compilation 44 93-102.

33. Schwarzer R, Luszczynska A (2008) How to overcome health-compromising behaviors: The health action process approach. Journal of A European Psychologist 13: 141-151.

34. Schwarzer R, Mueller J (1998) Assesment of percieved general self_efficacy on the internet: data callection in cyberspace. Anxiety Stress and Coping 12 145-161.

35. Saif Ali A (2015) Change Behavior and Behavior Therapy: Theory and Methods. Tehran: time.

36. Shafiabadi A (2002) Group dynamics and group counseling, Tehran: Growth.

37. Thompson E, Thomas H, Lars-Göran O (2009) Intensive Treatment of Specific Phobias in Children and Adolescents. Cognitive and Behavioral Practice 16: 294-303.

38. Tork Laudan F (2010) Efficacy of success in life. School counselor 6: 7-4.

39. Zare Bahram Abadi M, Nazari, e-Taiba (2014) The effectiveness of cognitive behavioral group therapy on depression and self-managing women of femaleheaded households. Journal of Clinical Psychology 14: 94-83.

40. Zettle Robert D (2005) The Evolution of a Contextual Approach to Therapy: From Comprehensive Distancing to ACT. International Journal of Behavioral and Consultation Therapy 1: 77-89. 